\title{
Spatial and Temporal Changes and Driving Factors of Desertification in the Source Region of the Yellow River, China
}

\author{
Q. G. Liu*† and Y. F. Huang** \\ *Department of Tourism and Geography, Hefei University, Hefei 230601, China \\ ** Department of Biology Food and Environment, Hefei University, Hefei 230601, China \\ †Corresponding author: Q. G. Liu; qgliuhf@163.com
}

Nat. Env. \& Poll. Tech. Website: www.neptjournal.com

Received: 03-12-2019

Revised: $21-01-2020$

Accepted: 01-03-2020

Key Words:

Yellow river

Desertification

Spatial and temporal

changes

Remote sensing

\begin{abstract}
The source region of the Yellow River, located in the north-eastern edge of the Qinghai-Tibet Plateau, is an important water conservation region and ecological barrier of the Yellow River. In this paper, based on remote sensing technology, multi-period Landsat remote sensing images in the source region were taken as the main information source. With the assistance of field investigation, we monitored the spatial and temporal changes of desertification in the source region from 2000 to 2019. The results show that the area of desertification in the source region has accounted for $9.36 \%$ of the total area, of which the light desertification land is the major portion. The desertification is mainly distributed between the southern margin of Madoi Valley basin and the northern margin of Heihe Valley basin, and is distributed on the river valleys, lakesides, ancient rivers and piedmont proluvial fan, showing the form of patches, sheets and belts. The growth rate of desertification in the source region was $87.47 \%$ from 2000 to 2010 . With a high growth rate, the process of desertification was represented by the rapid spread of desertification. From 2010 to 2019, the growth rate of desertification was $37.32 \%$, which was relatively slow. But the moderate desertification land maintained a straight linear growth trend, showing an increasing trend of desertification degree. Through the analysis of the driving factors of desertification in the source region of the Yellow River, this paper argues that the special geographical location, climatic factors, rodent damages and human activities are the main causes of desertification.
\end{abstract}

\section{INTRODUCTION}

Desertification is one of the major ecological and environmental problems facing China. The source region of the Yellow River is located in the northeast of the Qinghai-Tibet Plateau, which is the transition zone from the Qinghai-Tibet Plateau to the Loess Plateau. It is an important water conservation region and ecological barrier of the Yellow River, and also a sensitive area of climate changes. Due to the harsh natural conditions and fragile ecological environment, and the impact of global climate changes and human activities, since the 1980s, many ecological and environmental problems have emerged in the source region of the Yellow River, such as desertification, grassland degradation, glacial recession, permafrost melting, and the flow interruption of the Yellow River. The overall eco-environment in the source region of the Yellow River is deteriorating, and desertification is the most serious ecological and environmental problems. A series of ecological and environmental problems dominated by land desertification, have seriously affected the sustainable economic development and social stability of the source region and had a certain impact on the middle and lower reaches of the Yellow River (Cheng 1998, Zeng et al. 2003, Wang et al. 2004).
At present, the research on desertification is relatively weak in the source region of the Yellow River, which has affected the governance of desertification and the reconstruction of eco-environment in alpine regions. Monitoring and assessment of desertification is an important way to scientifically and effectively prevent desertification. Remote sensing with a wide range of observations, a large amount of information, a fast update of data and high accuracy (Kang \& Liu 2014, Ma et al. 2016), has been widely used in the monitoring and assessment of desertification. Based on RS image processing technology, this paper used Landsat TM/ETM+ remote sensing images from 2000 to 2019, analysed the spatial and temporal changes of desertification in the source region of Yellow River since 2000 , explored the driving factors of desertification. Base on the analysis of the development trend of desertification, this paper provides a relevant scientific and theoretical basis for the restoration of desertification and eco-environment management in the source region of the Yellow River.

\section{STUDY AREA}

The source region of the Yellow River generally refers to the river basin above Duoshixia (Institute of Geography, CAS 


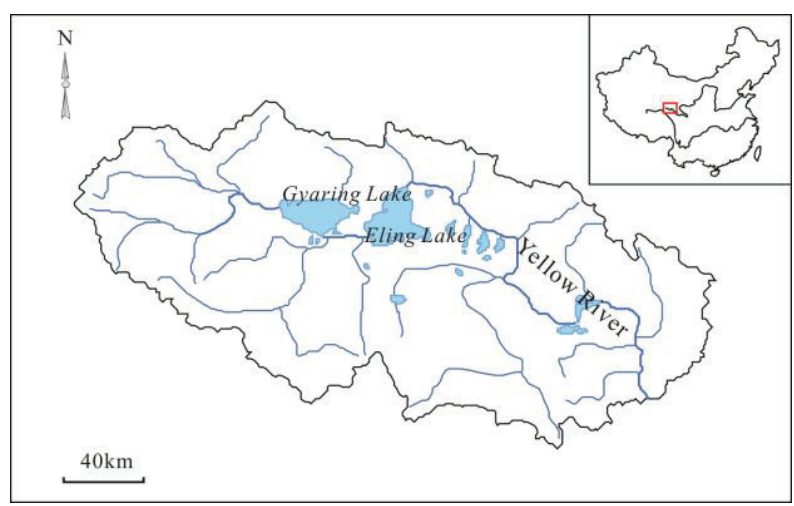

Fig. 1: Geographic location of the study area in China.

1990). To more completely study the desertification in the source region of the Yellow River, our study focused on the river basin above Tehetu Township. The study area is located between $33^{\circ} 42^{\prime} \sim 35^{\circ} 20^{\prime} \mathrm{N}$ and $95^{\circ} 52^{\prime} \sim 99^{\circ} 29^{\prime} \mathrm{E}$, with an area approximately $3.7 \times 10^{4} \mathrm{~km}^{2}$ (Fig. 1). The source region of the Yellow River is bounded by Kariqiong Mountain in the west, Bayan Har Mountain in the south, Buqing Mountain in the north and Amne Machin Mountain in the east. It belongs to Qinghai Province, includes most parts of Madoi County and a part of Darlag County and Maqen County in Golog Tibetan Autonomous Prefecture, as well as includes a part of Qumarleb County and Chindu County in Yushu Tibetan Autonomous Prefecture.

The source region of the Yellow River is high in the northwest and low in the southeast, and the elevation of most areas is $4,100-4,600 \mathrm{~m}$. The central area is relatively open, with numerous lakes and marshes, surrounded by icebergs and snow-capped peaks. The landform shows the characteristics of inter-distribution of low mountains, wide valleys and lake basins. The source region is a typical continental alpine climate, characterized by cold and dry weather, the sharp difference in temperature, much wind and snow, and violent climate changes. The annual mean temperature is $-3.5^{\circ} \mathrm{C}$, annual mean precipitation is $312 \mathrm{~mm}$, and annual mean evaporation is $1,240-1,327.9 \mathrm{~mm}$. The temperature and precipitation decrease from southeast to northwest, and the trend of precipitation increasing with altitude is also obvious. Alpine cold meadow (ACM) and alpine cold steppe (ACST) are the main vegetation types in the source region of the Yellow River.

\section{MATERIALS AND METHODS}

Desertification land classification: The classification of desertification land is an objective reflection of the degree of land degradation. In this paper, based on the existing standards and methods for the division of desertification
(Wang et al. 1998), through field investigation and laboratory analysis, and combined with the changes of vegetation, soil and other factors, the desertification land in the source region of the Yellow River can be divided into light desertification land (LDL), moderate desertification land (MDL), severe desertification land (SDL) and extremely desertification land (EDL). All types of desertification were mainly distinguished by the degree of land degradation.

$\boldsymbol{L D L}$ : the area of quicksand is under $5 \%$, and there is almost no wind-sand flow. The vegetation coverage is over 30\%, mainly distributed in fixed coppice sandbags and sporadic grassland. Most of the surface remains in the state of native grassland. There is a small amount of wind erosion and wind deposition, and the surface appears spot-like quicksand, which is equivalent to fixed sand.

$M D L$ : the area of quicksand is 5-25\%, and the wind-sand flow is not obvious. Semi-fixed sand and semi-naked gravel are distributed in patches. The vegetation coverage is $20-30 \%$, and there are some sporadic sand dunes. Grassland has been significantly degraded, and the important constructive species of native vegetation has taken a secondary position, while the sandy vegetation has become the main species. Flaked quicksand and coppice dune have appeared in large numbers, which is equivalent to semi-fixed sand.

$S D L$ : the area of quicksand is $25-50 \%$, the wind-sand flow and the quicksand texture are obvious, with irregular patch distribution, and the sand dunes are clearly visible. The vegetation coverage is $10-20 \%$, and there are coppices in the topsoil. The native vegetation no longer exists, sandy grass coppices are dominant species, and the wind erosion and wind landform are obvious.

$\boldsymbol{E D L}$ : the area of quicksand is over 50\%, and large areas of sand land are distributed continuously. Sand dune, dune ridge and other landforms are obvious. The vegetation coverage is under $10 \%$. The original surface form has been completely destroyed and replaced by quicksand. 
Data sources and processing: In this paper, Landsat TM images obtained in 2000 and 2010, and Landsat ETM+ images obtained in 2019 were used to establish databases for desertification monitoring. To reduce the influence of seasonal aspect and cloud cover on monitoring, remote sensing images with cloud cover less than $10 \%$ in summer and autumn were selected as far as possible. ATCOR atmospheric correction module of PCI image processing software was used for radiation correction to obtain surface reflectance images. The geometric correction was based on the topographic map with a scale of 1:50,000, control points were selected from the topographic map, and the quadratic polynomial re-sampling was selected to correct them. The correction accuracy was controlled within 0.5 pixels, and the ground resolution was controlled within $30 \mathrm{~m} \times 30 \mathrm{~m}$. Then, with the support of ARC/INFO software, based on the data of soil, vegetation and meteorology in the source region of the Yellow River, the human-computer interactive interpretation was used to extract the data.

Desertification difference index model: In this paper, the normalized differential vegetation index (NDVI) reflecting vegetation coverage was adopted to indicate the desertification degree, because vegetation coverage is generally considered as a good indicator of desertification. The NDVI was calculated using reflectance data from infrared and near-infrared bands of Landsat TM/ETM+ images after radiation and geometric correction. The surface albedo of the study area was estimated by using Landsat TM data inversion model (1) established by Liang (2000).

albedo $=0.356 \rho_{T M 1}+0.130 \rho_{T M 3}+0.373 \rho_{T M 4}+0.085 \rho_{T M 5}+0.072 \rho_{T M 7}-0.0018$

Based on the spatial characteristics of Albedo-NDVI, a desertification difference index model in the study area was established. The model was used to obtain multi-temporal desertification index images. The detailed process was referred to relevant literature (Zeng et al. 2006). The desertification difference index model can be expressed as:

$$
\text { DDI }=1.3437 \mathrm{NDVI} \text {-albedo }
$$

Monitoring information extraction: According to the data obtained from two field surveys in 2018 and 2019, combined with the map data of the vegetation type, soil type and geology of the study area, through the means of visual interpretation, the typical sample areas of different desertification types were selected and determined on Landsat ETM+ images obtained in 2019. With the support of image processing software, the connection between the typical sample areas and the desertification difference index images was established to determine the position of the typical sample areas on the desertification difference index images. The DDI values of different desertification types were calculated, and the monitoring indicators of different desertification types were finally determined (Table 1). Based on the monitoring indicators given in Table 1, the spatial distribution characteristics of desertification in 2000, 2010 and 2019 were obtained. Using the change monitoring tool in ENVI software, the raster data of desertification distribution during our study period were statistically analysed, the transfer matrix of desertification was obtained, and the temporal changes of desertification were further analysed.

\section{RESULTS AND ANALYSIS}

The spatial changes of desertification: In this paper, the remote sensing monitoring results of desertification in 2000, 2010 and 2019 in the source region of the Yellow River were obtained. Based on the monitoring results in 2019, the current situation and spatial distribution characteristics of desertification in the source region were analysed. In 2019, the area of desertification in the source region has reached $3,519.97 \mathrm{~km}^{2}$, accounting for $9.36 \%$ of the total area, among which the LDL was the largest, accounting for $45.82 \%$ of the total area of desertification, the MDL followed, accounting for $26.20 \%$. The area of the SDL was close to that of the EDL, accounting for $13.80 \%$ and $14.18 \%$ respectively. According to the China Desertification Census data in 2015, the total area of desertification on the Qinghai-Tibet Plateau reached $313,274.62 \mathrm{~km}^{2}$, accounting for $13.96 \%$ of the total area of the plateau. According to the above data, the area ratio of desertification in the source region of the Yellow River is slightly lower than the average level of the whole Qinghai-Tibet Plateau.

However, the distribution of all types of desertification in the source region was relatively concentrated. Except for a small area of desertification to the west of the Eling Lake, most of the rest were distributed to the east of the Eling Lake. From the perspective of geomorphic units, desertification was concentrated between the southern margin of Madoi wide valley basin and the northern margin of Heihe River wide valley basin. It was in the form of patches, sheet and bands, distributed along the low mountains and hills that run northwest to southeast, and distributed in the river valleys, lakesides, ancient rivers and piedmont proluvium fans, etc.

According to the administrative division, the distribution of desertification in the source region was concentrated in Madoi County. The area of desertification in Madoi County accounted for $85.07 \%$ of that in the source region. All types of desertification in Madoi County were more than $78 \%$ of those in the source region. In order of proportion, from large to small, they were LDL, MDL, SDL and EDL respectively. The LDL and the MDL were the main ones, and the SDL 
and the EDL also occupy a large proportion. The proportion of desertification land in Madoi County was much higher than the average level of Qinghai-Tibet Plateau. The area of desertification in Maqen County accounted for $11.71 \%$ of that in the source region. The remaining three counties, Qumarleb County, Chindu County and Darlag County, had a very small area of desertification. Overall, the average degree of desertification in the source region was not the highest in the Qinghai-Tibet Plateau. However, from the local area, the degree of desertification and damage in the source region was relatively high.

\section{The dynamic changes of desertification in the 2000s:} The monitoring results of desertification from 2000 to 2010 (Table 2 and Table 3) show that the area of desertification in the source region increased from $1,474.71 \mathrm{~km}^{2}$ to $2,768.61 \mathrm{~km}^{2}$, with a growth rate of $87.47 \%$ and an annual mean growth rate of $21.87 \%$. Among them, the SDL increased the fastest, with an annual mean growth rate of $69.52 \%$. The MDL and the LDL were followed, with an annual mean growth rate of $28.62 \%$ and $25.32 \%$, respectively. The EDL increased more slowly, with an annual mean growth rate of only $0.71 \%$. It can be seen that the changes of desertification in the source region in the 2000s, not only showed the rapid spread of desertification but also showed that the degree of desertification increased year by year.

The dynamic analysis of desertification mentioned above only reflected the overall situations of desertification in the source region of the Yellow River. In fact, in the process of dynamic changes of desertification, the expansion and reversal of desertification were two coexisting processes at the same time, and the final result of desertification depends on which process was dominant. The expansion of desertification indicated its spread and aggravation, while the reversal of desertification indicated improving in natural environmental conditions, weakening in human activities, and reducing in the area of desertification in the source region. To effectively analyse the process of desertification in the source region, according to the characteristics of the dynamic changes of desertification, the desertification in the 2000s was divided into three types: expansion type, reversal type and stabilization type. The expansion type refers to the region where the area of desertification expanded and degree of desertification increased. The reversal type refers to the region where the process of desertification reversed, the area of desertification reduced and the degree of desertification weakened. The stabilization type refers to the region where the desertification was maintaining its initial state.

The monitoring results of two-time phases in 2000 and 2010 were analysed by GIS spatial superposition, taking 2000 as the benchmark, and this paper concluded that the area of expansion type desertification was $1,938.8 \mathrm{~km}^{2}$ from 2000 to 2010 , of which $1,401.54 \mathrm{~km}^{2}$ was transferred from the original non-desertification, and the remaining $537.26 \mathrm{~km}^{2}$ was from the original desertification aggravated by different degrees. The area of expansion type desertification accounted for $36.43 \%$ of the total area of desertification. The area of reversal type desertification was $319.73 \mathrm{~km}^{2}$, accounting for $21.68 \%$. The area of stabilization type desertification was $617.72 \mathrm{~km}^{2}$, accounting for $41.89 \%$. In the $2000 \mathrm{~s}$, the annual mean expansion rate of desertification was $32.86 \%$, while the annual mean reversal rate was only $5.42 \%$, and

Table 1: Desertification detecting indicator in the source region of the Yellow River.

\begin{tabular}{|lllll|}
\hline Desertification type & LDL & MDL & SDL & EDL \\
\hline DDI value & $51-63$ & $43-50$ & $34-42$ & $23-33$ \\
\hline
\end{tabular}

Table 2: Desertification land in the source region of the Yellow River from 2000 to 2010 (unit: $\mathrm{km}^{2}$ ).

\begin{tabular}{|c|c|c|c|c|c|}
\hline Desertification type & 2000 & 2010 & Area Change & Change rate $\%$ & Annual change rate $\%$ \\
\hline EDL & 417.34 & 429.11 & 11.77 & 2.82 & 0.70 \\
\hline SDL & 95.21 & 360.00 & 264.79 & 278.10 & 69.52 \\
\hline MDL & 295.43 & 633.61 & 338.18 & 114.47 & 28.62 \\
\hline LDL & 666.73 & $1,341.89$ & 675.16 & 101.26 & 25.32 \\
\hline Total & 147.71 & $2,764.61$ & $1,289.90$ & 87.47 & 21.87 \\
\hline
\end{tabular}

Table 3: Transfer Matrix of desertification land conversion in the source region of the Yellow River from 2000 to 2010 (unit: $\mathrm{km}^{2}$ ).

\begin{tabular}{|lllllll|}
\hline \multirow{2}{*}{2000} & 2010 & & & & & \\
& Water area & EDL & SDL & MDL & LDL & Non-desertification \\
\hline Water area & $1,411.92$ & 5.92 & 4.45 & 4.88 & 6.88 & 36.81 \\
EDL & 12.02 & 267.65 & 65.72 & 38.65 & 21.46 & 11.84 \\
SDL & 2.18 & 23.74 & 31.09 & 24.11 & 11.47 & 2.62 \\
MDL & 6.24 & 59.00 & 80.67 & 91.74 & 46.65 & 11.13 \\
LDL & 12.97 & 45.35 & 107.55 & 220.96 & 227.24 & 52.84 \\
Non-desertification & 65.83 & 27.45 & 70.52 & 253.27 & $1,028.19$ & $33,196.91$ \\
\hline
\end{tabular}


Table 4: Desertification land in the source region of the Yellow River from 2010 to 2019 (unit: $\mathrm{km}^{2}$ ).

\begin{tabular}{|llllll|}
\hline Desertification type & 2010 & 2019 & Area Change & Change rate \% & Annual change rate \% \\
\hline EDL & 429.11 & 499.10 & 69.99 & 16.31 & 1.63 \\
SDL & 360.00 & 486.10 & 126.10 & 35.03 & 3.50 \\
MDL & 633.61 & 922.07 & 288.46 & 45.53 & 4.55 \\
LDL & $1,341.89$ & $1,612.70$ & 270.81 & 20.18 & 2.02 \\
Total & $2,764.61$ & $3,519.97$ & 755.36 & 37.32 & 2.73 \\
\hline
\end{tabular}

Table 5: Transfer matrix of desertification land conversion in the source region of the Yellow River from 2010 to 2019 (unit: $\mathrm{km}^{2}$ ).

\begin{tabular}{|lllllll|}
\hline \multirow{2}{*}{2010} & 2019 & & & & & \\
\cline { 2 - 6 } & Water area & EDL & SDL & MDL & LDL & Non-desertification \\
\hline Water area & $1,401.59$ & 13.24 & 9.42 & 16.72 & 10.72 & 59.30 \\
EDL & 10.97 & 300.11 & 65.84 & 35.92 & 13.35 & 2.92 \\
SDL & 15.05 & 92.44 & 129.01 & 89.54 & 32.58 & 1.38 \\
MDL & 16.07 & 52.62 & 156.89 & 261.22 & 145.26 & 1.55 \\
LDL & 15.53 & 26.29 & 106.87 & 400.22 & 789.36 & 3.62 \\
Non-desertification & 41.03 & 14.40 & 18.07 & 118.45 & 621.43 & $32,498.74$ \\
\hline
\end{tabular}

the annual mean expansion rate was six times of the annual mean reversal rate. Therefore, in the 2000 s, the process of desertification in the source region not only shows the rapid spread of desertification but also shows the increasing degree of desertification year by year, reflecting the serious degradation of land and the worsening of eco-environment in the source region during this period.

The dynamic changes of desertification in the 2010s: In Table 4 and Table 5, the monitoring results of desertification from 2010 to 2019 show that desertification in the source region was further expanded in the 2010s. From 2010 to 2019, the desertification expanded by $755.36 \mathrm{~km}^{2}$, with an annual mean expansion rate of $2.73 \%$, which was lower than that in the 2000s. In the 2010s, the changes of desertification were characterized by the rapid growth of MDL and SDL. The annual mean expansion rate of EDL reached $1.63 \%$, exceeding that in the 2000s.

Taking 2010 as the benchmark, the desertification in the 2010s was divided into three types: expansion type, reversal type and stability type. The area of expansion type desertification was $1,607.69 \mathrm{~km}^{2}$, of which $772.37 \mathrm{~km}^{2}$ was transferred from the original non-desertification, and the remaining $835.32 \mathrm{~km}^{2}$ was aggravated by different degrees. In the 2010s, the annual mean expansion rate of desertification was $5.82 \%$, while the annual mean reversal rate was $1.63 \%$, and the annual mean expansion rate was about four times of the annual mean reversal rate. From the above analysis, it shows that although the expansion rate of desertification in the 2010s was lower than that in the 2000s, the desertification in the source region still maintained a trend of continuous expansion in the 2010s, with the aggravation of the desertification as the main factor. In the 2010s, the desertification in the source region was in the stage of development to strong development, which was consistent with the overall situations of desertification development in the whole Qinghai-Tibet Plateau. If the situations should be not controlled, the desertification in the source region will expand further.

\section{DRIVING FACTORS OF DESERTIFICATION}

Desertification is a complex process of land degradation. Its expansion and reversal are influenced by both natural conditions and human activities. When natural conditions deteriorate and the intensity of human activities exceeds the environmental carrying capacity, desertification will intensify and expand. On the contrary, when natural conditions improve and human activities are effectively controlled, desertification can be reversed. Due to the special geographical location of the source region, the climate changes, rodent damages and human activities are the main causes of desertification.

Climatic factors: The source region of the Yellow River is located in the hinterland of the Qinghai-Tibet Plateau. Under special geographical conditions, it has formed a special climate. Climate changes in the source region are an important cause of desertification. There are two main aspects of climate change, one is rising temperatures, and the other is declining precipitation. According to meteorological data, the annual mean temperature in the source region has been increasing slowly in the past 60 years (Fig. 2), and the temperature increased by $0.382^{\circ} \mathrm{C}$ per $10 \mathrm{a}$. The variation trends of annual mean temperature are bounded by 1986 . Before 1986 , the temperature decreased by $0.149^{\circ} \mathrm{C}$ per $10 \mathrm{a}$. 


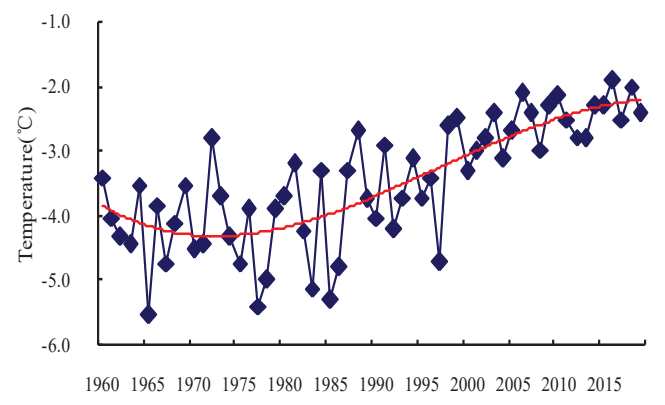

Fig. 2: The change of annual mean temperature from 1960 to 2019.

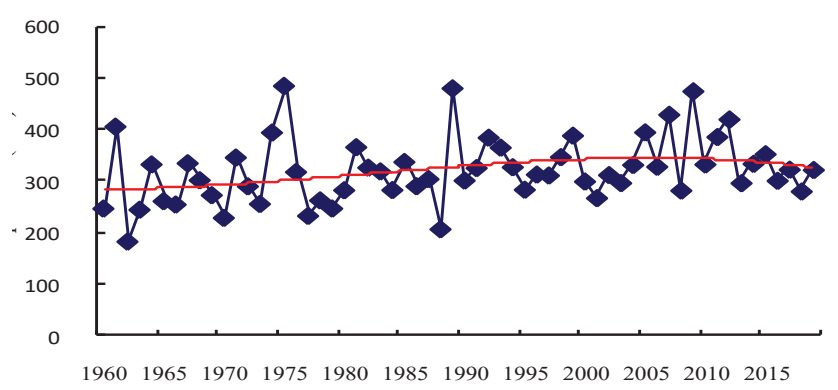

Fig. 3: The change of annual mean precipitation from 1960 to 2019.

Since 1986 , the temperature increased by $0.557^{\circ} \mathrm{C}$ per $10 \mathrm{a}$. Therefore, the increasing stage of annual mean temperature in the source region mainly occurred after 1986. The change of annual mean precipitation in the source region is also obvious (Fig. 3), and the inter-annual change is over $300 \mathrm{~mm}$. The annual mean precipitation in the source region is $312 \mathrm{~mm}$, and the annual mean evaporation is over $1,240 \mathrm{~mm}$, causing serious water shortage. Since 2000, the five-year drought has caused changeable windy weather and accelerated the process of desertification.

An important consequence of climate change is the impact on the permafrost environment. There is a large area of permafrost in the source region of the Yellow River. Permafrost has an important influence on the growth of alpine meadow vegetation. On the one hand, the permafrost can effectively prevent surface water and soil water from infiltrating, thereby increasing the water content of the plant root area. On the other hand, the permafrost has the function of gathering nutrients from the upper layers, because lower soil temperature is conducive to the accumulation of organic matter. Many studies have shown that the mean temperature of the upper permafrost has increased by $0.2-0.3^{\circ} \mathrm{C}$ in the past 60 years due to climate warming, resulting in large-scale thawing of permafrost, and even the disappearance of per- mafrost in some areas. As a result, the water content of plant roots decreased, swamps and lakes dried up, soil structure and composition changed, and finally, desertification intensified.

Another important consequence of climate change is the impact on the water environment. According to the survey data, the lake area decreased by $0.54 \%$ from 1970 to 1980 , while the lake area decreased by $9.3 \%$ from 1980 to 1990 . The water level of the lake generally decreased by $2-3 \mathrm{~m}$, and the lake shrank about 20-30m. From 1990 to 2019, the area of swamp and lake both decreased by about $10 \%$, while the reduction of river area was the highest, reaching over $22 \%$. The area of swamp shrank by nearly $200 \mathrm{~km}^{2}$, and the number of lakes decreased by 49 .

Rodent damages: Rodent damages are the main biological disasters that destroy the grassland ecology in the source region of the Yellow River. The rodent damages in the source region have a long history, but they have been especially serious since 1985. The main rodents in the source region are Myospalax baileyi and Ochotona curzoniae, among which Ochotona curzoniae is the most widely distributed and the most harmful. According to statistics, the area of the grassland affected by rodent damages in the source region is $149.95 \times 10^{4} \mathrm{hm}^{2}$, accounting for $65.20 \%$ of the natural grassland. The average density of rodent holes is $3,750-7,050 / \mathrm{hm}^{2}$, 
and the serious area is $19,860 / \mathrm{hm}^{2}$. Rodents feed on the roots and stems of plants, and cut off the roots, causing large areas of grassland to wither and die, resulting in degradation and desertification of grassland. More than $50 \%$ of the "black soil type" degraded grassland in the source region is caused by rodent damages. According to the measurement, the water content of the surface soil of the secondary bare land on the shady and sunny slopes affected by rodent damages is $22.18 \%$ and $29.27 \%$ lower than that of the native grassland respectively. These rodent holes and "black soil beach" in the grassland become the breach of wind erosion, creating conditions for wind erosion, and accelerating degradation and desertification of grassland.

Human activities: Human activities are one of the important factors affecting the ecological environment in the source region, which are closely related to the changes of desertification. Especially in the process of economic development, human factors have become the leading factors affecting the changes of desertification (Chen et al. 2016). Unreasonable human activities destroy the surface ecosystem and lead to desertification.

The industrial structure of the source region is dominated by animal husbandry. Most of the economic income of herdsmen depends on animal husbandry, and expanding the number of livestock is the main way of economic growth. Since the end of 1960s, the animal husbandry in the source region has developed rapidly, the number of livestock has multiplied, and the grassland has been in the state of overloading, resulting in the continuous degradation of the grassland. In the source region, the area of grassland is small in winter and spring, the grazing time is long, and the overloading is more serious. Especially in the beach near the water source, the middle and lower part of the hillside and the two sides of the river valley, the overloading of grassland is frequent, which aggravates the load of grassland in winter and spring. According to the investigation of Wang (2001) on the grassland in the source region of the Yellow River, the theoretical stocking rate of the local grassland was 667,000 sheep units in winter and $3,048,900$ sheep units in summer. From 2000 to 2019, the overloading rate of grassland in summer and winter in the source region reached $66.98 \%$ and $100 \%$ respectively. In winter and spring, the quantity of forage grass is the low quantity and poor quality, and in summer and autumn, the amount of forage is many quantities and high quality, which leads to the vicious cycle of livestock being fat in autumn, thin in winter and death in spring.

Another reason for the destruction of natural resources and the ecological environment by human activities is the improper use of water and soil resources, excessive mining, and indiscriminate digging. The source region of the Yellow River is rich in natural resources. Gold, salt and other minerals, as well as wild animals such as Gymnocypris przewalskii, Vulpes corsac and Vulpes vulpes are the main objects for local residents to engage in sideline business. According to the data of the grassland general station of Qinghai province, since 1980, sand gold production has started in the area around Daqing Mountain, and thousands of gold miners from other places have flocked to the area to collect gold and salt, catch fish and hunt natural enemies of wild rodents. Excessive mining, indiscriminate digging and illegal hunting have destroyed large areas of grassland vegetation, reduced the natural enemies of rodents, damaged the ecosystem, and further led to soil erosion and desertification. The grassland on both sides of the river has degenerated, the function of water conservation has declined, which has artificially aggravated the land desertification.

\section{DISCUSSION AND CONCLUSIONS}

Distribution of desertification land: The area of desertification land in the source region of the Yellow River accounts for $9.36 \%$ of the total area, which is about $4.59 \%$ lower than that in the whole Qinghai-Tibet Plateau. However, the desertification land in the source region of the Yellow River is concentrated in Madoi County. The area of desertification land in Madoi County accounts for 14.3\% of the total area, which is higher than that in the whole Qinghai-Tibet Plateau. The proportion is higher in the Huanghe Township and Heihe Township, where the desertification is concentrated. Therefore, on the whole, the area of desertification land in the source region is small, but the distribution of desertification land is relatively concentrated. In some areas, the proportion of desertification land is high, and the degree of desertification is also high.

The general situation of desertification expansion: During the 20 years from 2000 to 2019, the area of desertification land in the source region of the Yellow River increased by $2,045.26 \mathrm{~km}^{2}$. Among them, LDL accounts for $46.25 \%$, MDL accounts for $30.64 \%$, SDL accounts for $19.11 \%$, and EDL accounts for the smallest proportion, only $4 \%$. The results show that the desertification in the source region is increasing rapidly, among which LDL and MDL are expanding significantly. Since the 2000s, the process of desertification in the source region has presented a trend of rapid development, but the development of desertification in different periods showed different characteristics. In the 2000s, the growth rate of desertification was high, and the process of desertification was characterized by the rapid spread of desertification land. In the 2010s, the growth rate of desertification slowed down relatively, but MDL maintained a linear growth trend. In the past 20 years, although there is a certain reversal of desertification in some areas, on the whole, the source region is dominated by the expansion of desertification. 
The results of driving force analysis of desertification: In the past 20 years, the desertification in the source region was attributed to the unreasonable exploitation and utilization of grassland resources under the background of the warming and drying trend of the alpine ecological environment, which further exacerbated the process of grassland degradation and land desertification. Due to the combined action of natural and human factors, many lakes and wetlands in the source region have shrunk or even dried up, causing a series of ecological environment problems such as grassland degradation, land desertification and soil erosion.

\section{ACKNOWLEDGEMENT}

This research was financially supported by the Project of Anhui Education Department (No. SK2018A0603). The work was facilitated by the Qinghai Department of Lands, Environment and Resources and the Project of Scientific Research and Development Foundation of Hefei University (No. 20RW06ZDA).

\section{REFERENCES}

Chen, L., Ding, W., Geng, Y. and Zhao, C. 2016. Dynamic change trend of desertification in Dulan County during 1975-2015. Desert and Oasis Meteorology, 10(5): 64-71.
Cheng, G. 1998. Some understandings about the eco-environmental protection and buildings in the source region of Yangtze and Yellow rivers. Advance in Earth Sciences, 13(suppl.): 1-5.

Institute of Geography, CAS. 1990. The Atlas of Qinghai-Tibetan Plateau. Science Press, pp. 77-79.

Kang, W. and Liu, S. 2014. A review of remote sensing monitoring and quantitative assessment of aeolian desertification. Journal of Desert Research, 34(5): 1222-1229.

Liang, S. 2000. Narrowband to broadband conversions of land surface albedo I: Algorithms. Remote Sensing of Environment, 76: 213-238.

Ma, Y., Sha, Z., Chen, X. and Fu, G. 2016. Desertificated land changes in Gonghe basin from 1990 to 2010. Journal of Arid Land Resources and Environment, 30(2): 176-181.

Wang, G. 2001. Eco-environmental degradation and causal analysis in the source region of the Yellow River. Environmental Geology, 40(7): 884-890.

Wang, G., Ding, Y., Wang, J. and Liu, S. 2004. Land ecological changes and evolutional patterns in the source regions of the Yangtze and Yellow rivers in recent 15 years. Acta Geographica Sinica, 59(2): 163-173.

Wang, T., Wu, W. and Wang, X. 1998. Remote sensing monitoring and assessing sandy desertification: An example from the sandy desertification region of northern China. Quaternary Sciences, 2: 108-118.

Zeng, Y., Feng, Z. and Cao, G. 2003. Land-cover change and its impacts on environment in the upper reach of the Yellow River, northeast Qinghai-Tibetan Plateau. Mountain Research and Development, 23(4): 353-361.

Zeng, Y., Xiang, N. and Feng, Z. 2006. Albedo-NDVI space and remote sensing synthesis index models for desertification detection. Scientia Geographica Sinica, 26(1): 75-81. 